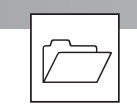

Endokrynologia Polska

DOI: $10.5603 /$ EP.a2021.0054

Volume/Tom 72; Number/Numer 4/2021 ISSN 0423-104X, e-ISSN 2299-8306

\title{
Cardiac dysfunction associated with consumptive hypothyroidism in a case of hepatic haemangioma
}

\author{
Zhichao Zheng ${ }^{\circledR}$, Youli Li ${ }^{\circledR}$, Liying Wang ${ }^{\circledR}$, Chengjun Dai ${ }^{\circledR}$, Jieqi Qian ${ }^{\circledR}$, Chaoban Wang ${ }^{\circledR}$, \\ Xiaoou Shan ${ }^{\circ}$ \\ Department of Paediatrics, The Second Affiliated Hospital and Yuying Children's Hospital of Wenzhou Medical University, \\ Wenzhou, Zhejiang, China
}

Key words: hepatic haemangioma; consumptive hypothyroidism; cardiac dysfunction

A two-month-old girl had severe hypothyroidism and was referred to our hospital. She was born at 37 weeks of gestation after a normal pregnancy. Her birth weight was $3200 \mathrm{~g}$. A physical examination indicated that there were two purple skin lesions on her left shoulder and right groin, and her liver was larger than normal, $4 \mathrm{~cm}$ below the right costal margin. Abdominal ultrasonography demonstrated multiple hypoechoic lesions throughout the liver. No arteriovenous shunt was found. MRI of the hepatic parenchyma (Fig. 1) confirmed innumerable lesions with near-total hepatic parenchymal replacement. No other abnormality was evident on physical examination.

Thyroid function examination suggested an elevated thyroid-stimulating hormone (TSH) of over 150.00 $\mu \mathrm{IU} / \mathrm{mL}$ (Tab. 1), and low free triiodothyronine (FT3) was $1.24 \mathrm{pg} / \mathrm{mL}$. Thyroid ultrasonography showed mild

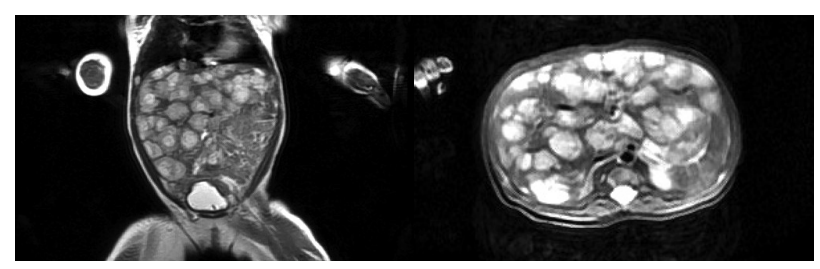

Figure 1. Abdominal MRI showing hepatic nodule enlargement of the thyroid. Thyroid-related antibodies were negative, and thyroglobulin (TG) was over 500 $\mathrm{ng} / \mathrm{mL}$ (normal value 3.5-77 $\mathrm{ng} / \mathrm{mL}$ ).

She started taking levothyroxine $50 \mathrm{mg} / \mathrm{d}$. Two weeks later, her TSH level was still over $150 \mu \mathrm{IU} / \mathrm{mL}$ (Tab. 1).

We thought that the infantile hepatic haemangiomas (IHHs) should be treated first. She was requested to take oral propranolol $(0.5 \mathrm{mg} / \mathrm{kg} / \mathrm{d})$ regularly. On the third day, the dose of propranolol was increased to $1 \mathrm{mg} / \mathrm{kg} / \mathrm{d}$. However, her heart rate dropped to $62 \mathrm{bpm}$. The echocardiography showed low left ventricular systolic function (Fig. 2AB). Brain natriuretic peptide (BNP) was 20,600 $\mathrm{pg} / \mathrm{mL}$ (normal value: $0 \sim 116 \mathrm{pg} / \mathrm{mL}$ ). She was thought to have developed cardiac insufficiency. Oral propranolol was suspended, and furosemide and spironolactone were given consecutively. However, these treatments did not improve the condition. At that time, we noticed that the patient's thyroid function was still abnormal. We increased the dose of levothyroxine to $100 \mu \mathrm{g} / \mathrm{d}$ (about $20 \mu \mathrm{g} / \mathrm{kg}$ ). Her heart rate became normal. Two weeks later, her heart ejection fraction improved, and the TSH concentration was decreased to a normal level (Tab. 1). She restarted propranolol again; it was increased to $2 \mathrm{mg} / \mathrm{kg} /$ day in about 3-4 weeks. On this occasion she did not have cardiac dysfunction. Subsequently she was discharged home.

Table 1. The results of the patient's thyroid hormone

\begin{tabular}{|c|c|c|c|c|c|}
\hline Age [months] & TSH $[\mu \mathrm{IU} / \mathrm{mL}]$ & $\mathrm{TT} 4[\mu \mathrm{g} / \mathrm{dL}]$ & TT3 [ng/mL] & FT4 [ng/dL] & FT3 [pg/mL] \\
\hline 2 & $>150,000$ & 7.41 & 0.38 & 0.94 & 1.24 \\
\hline 2.6 & $>150,000$ & 17.30 & 0.63 & 1.42 & 1.43 \\
\hline 3.5 & 2.34 & 22.62 & 0.699 & 3.78 & 2.82 \\
\hline 4.2 & 7.901 & 18.26 & 0.85 & 2.21 & 2.54 \\
\hline 8.8 & 1.740 & 19.16 & 1.11 & 2.58 & 3.45 \\
\hline
\end{tabular}

Normal value: TSH: $0.87-6.15 \mu \mathrm{lU} / \mathrm{mL} ;$ TT4: 6-13.2 $\mu \mathrm{g} / \mathrm{dL} ;$ TT3: $1.17-2.39 \mathrm{ng} / \mathrm{mL} ; \mathrm{FT4}$ : 0.94-1.44 ng/dL; FT3: 3.3-5.2 pg/mL 


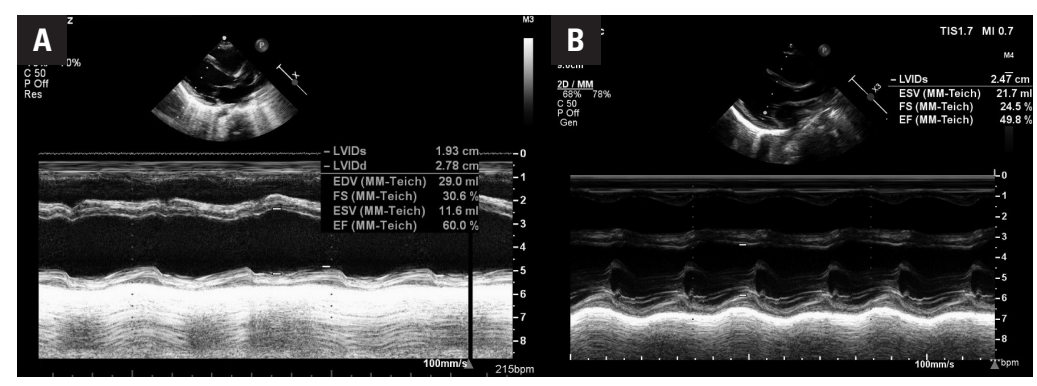

Figure 2. Echocardiograms showing the ejection fraction (EF) change. A. At age 2.1 months; $\boldsymbol{B}$. At age 2.8 months

We report a patient with diffuse haemangioma, who had severe hypothyroidism and extremely high levels of TG. She developed cardiac insufficiency after starting propranolol when her thyroid function still was abnormal. Fortunately, adequate doses of levothyroxine seemed to be effective for her cardiac insufficiency.

Cardiac insufficiency may occur in patients with IHHs. The causes of cardiac insufficiency are hypothyroidism and arteriovenous shunt [1]. Although our patient suffered from cardiac insufficiency, there was no evidence to show that she had an arteriovenous shunt. Interestingly, her cardiac function improved after receiving adequate levothyroxine. The T3 is considered as a critical regulator of cardiac chronotropic response and muscle tone [2], capable of enhancing the sensitivity of myocardial -adrenergic receptors to catecholamines, as well as exerting a positive inotropic effect and positive chronotropic action to the heart. Thus, hypothyroidism with low T3 can lead to bradycardia, and impaired ventricular systolic and diastolic function. Coincidentally, a low FT3 level, bradycardia, and impaired ventricular were presented in our patient. We reasonably believe that the patient's heart dysfunction was associated with hypothyroidism. A low FT3 level was mainly caused by type III deiodinase (D3). A hepatic haemangioma can secrete a large amount of D3, which causes a rise in T4 conversion to rT3 and a decrease in T3 [3]. Adding liothyronine may control hypothyroidism and improve cardiac insufficiency more rapidly [4]. Levothyroxine can reverse cardiac impairment caused by hypothyroidism. A combination of liothyronine and levothyroxine may be better in the early treatment stages of cardiac insufficiency. Our patient took levothyroxine alone because we did not have access to liothyronine, but it was still effective to use high-dose LT4. The patient started with propranolol $0.5 \mathrm{mg} / \mathrm{kg}$ and increased the dose rapidly, which may induce the aggravation of cardiac dysfunction. We think that the tolerance of patients should be fully considered when propranolol is used in the treatment of haemangioma. The dosage of the drug can be increased more slowly. Using a safe maximum dose of levothyroxine early in the treatment can help prevent the occurrence of heart failure.
Both our and Huang's cases showed that the patients had high TG levels [4]. It is different from congenital hypothyroidism. We speculate that considerably more TG-TH may be hydrolysed than normal under the stimulation of high TSH concentration. Also, the TG released into the blood is more than normal [5], which explains why consumptive hypothyroidism patients have a high TG level. Based on this fact, TG may be conducive to differential diagnosis.

In conclusion, early in the clinical course of illness, high-dose thyroid hormone replacement is as important as an anti-tumour treatment for these patients. Propranolol should be initiated at a lower dose of $0.25 \mathrm{mg} / \mathrm{kg} /$ day, and then increased up to $2 \mathrm{mg} / \mathrm{kg} / \mathrm{day}$ after about 3-4 weeks as tolerated. Extremely high TG levels can help to distinguish consumptive hypothyroidism from congenital hypothyroidism.

\section{Ethics approval and consent to participate Not applicable.}

\section{Consent for publication}

Written informed consent was obtained from the patient's legal guardian(s) for publication of this case report and any accompanying images.

\section{Conflict of interests}

The authors declare that they have no competing interests.

\section{Funding}

None declared.

\section{References}

1. Rialon KL, Murillo R, Fevurly RD, et al. Risk factors for mortality in patients with multifocal and diffuse hepatic hemangiomas. J Pediatr Surg. 2015; 50(5): 837-841, doi: 10.1016/j.jpedsurg.2014.09.056, indexed in Pubmed: 25783331.

2. Zaki SA, Dolas A. Refractory cardiogenic shock in an infant with congenital hypothyroidism. Indian J Crit Care Med. 2012; 16(3): 151-153, doi: 10.4103/0972-5229.102086, indexed in Pubmed: 23188956.

3. Bianco AC, Salvatore D, Gereben B, et al. Biochemistry, cellular and molecular biology, and physiological roles of the iodothyronine selenodeiodinases. Endocr Rev. 2002; 23(1): 38-89, doi: 10.1210/edrv.23.1.0455, indexed in Pubmed: 11844744

4. Huang SA, Tu HM, Harney JW, et al. Severe hypothyroidism caused by type 3 iodothyronine deiodinase in infantile hemangiomas. N Engl J Med. 2000; 343(3): 185-189, doi: 10.1056/NEJM200007203430305, indexed in Pubmed: 10900278.

5. Spencer CA, Wang CC. Thyroglobulin measurement. Techniques, clinical benefits, and pitfalls. Endocrinol Metab Clin North Am. 1995; 24(4): 841-863, indexed in Pubmed: 8608781. 